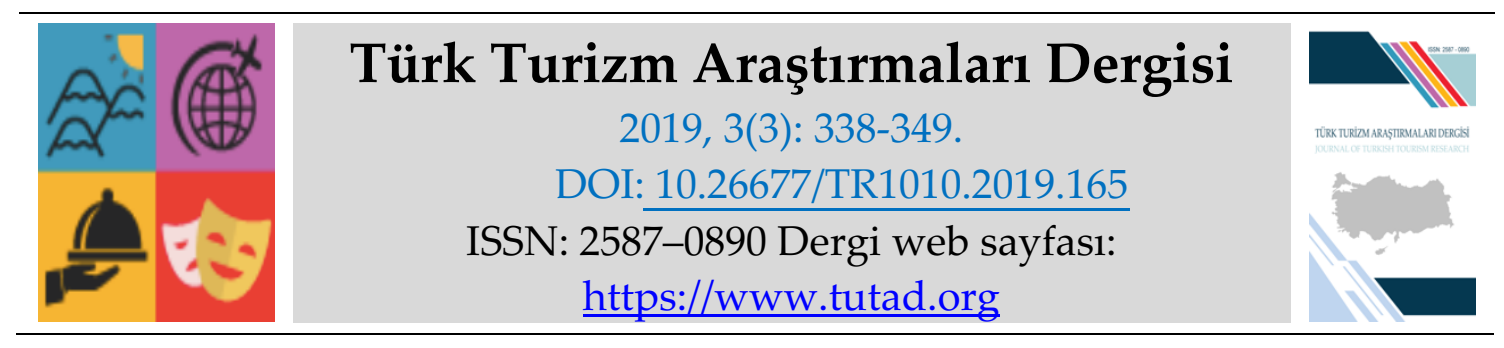

ARAȘTIRMA MAKALESI

\title{
Üniversite Öğrencilerinin Sürdürülebilirlik ve Sürdürülebilir Turizm Hakkındaki Bilgi Düzeyleri*
}

Dr. Öğr. Üyesi Hulusi Bi̇NBAŞIOĞLU, Malatya Turgut Özal Üniversitesi, Kale Turizm ve Otel İşletmeciliği MYO, Malatya, e-posta: hulusi.binbasioglu@ozal.edu.tr

ORCID: https://orcid.org/0000-0001-7488-8450

Dr. Öğr. Üyesi Aysun TUNA, İnönü Üniversitesi, Tasarım ve Güzel Sanatlar Fakültesi, Malatya, e-posta: aysun.tuna@inonu.edu.tr.

ORCID: https://orcid.org/0000-0001-5365-3273

Doç. Dr. Niyazi ÖZER, İnönü Üniversitesi, Eğitim Fakültesi, Malatya, e-posta: niyazi.ozer@inonu.edu.tr. ORCID: https://orcid.org/0000-0001-7745-6645

Prof. Dr. Süleyman Nihat ŞAD, İnönü Üniversitesi, Eğitim Fakültesi, Malatya, e-posta: nihat.sad@inonu.edu.tr ORCID: https://orcid.org/0000-0002-3169-2375

Öz

Bu çalışmada, üniversite öğrencilerinin sürdürülebilirlik ve sürdürülebilir turizm ile ilgili kavramlara ilişkin bilgi düzeylerinin ölçülmesi amaçlanmaktadır. Nicel araştırma geleneğine uygun olarak tasarlanan bu araştırmada betimsel ve nedensel karşılaştırmalı desen bir arada kullanılmıştır. Öğrencilerin ilgili kavramlara ne düzeyde aşina olduklarını belirlemek üzere elde edilen veriler üzerinden betimsel istatistik hesaplamaları yapılmıştır. Bu kavramlara ilişkin aşinalık düzeylerinin cinsiyet değişkeni açısından analizinde ise kay kare istatistiği kullanılmıştır. Yapılan analizler sonucunda öğrencilerin büyük bir çoğunluğunun iklim değişikliği, geri dönüşüm, kültürel çeşitlilik, ekosistemler ve biyo-çeşitliliğin korunması, atık yönetimi gibi sürdürülebilirlikle ilgili genel kavramlara aşina oldukları buna karşın karbon ayak izi, ekolojik ayak izi gibi teknik kavramlara ise çok aşina olmadıkları belirlenmiştir. Cinsiyet değişkeni açısından yapılan analizlerde ise yoksulluğu azaltma, karbon ayak izi ve ekolojik ayak izi konularında kadın ve erkek öğrencilerin görüşleri arasında anlamlı farklılıklar olduğu, erkek öğrencilerin kendilerini bu kavramlara daha aşina algıladıkları belirlenmiştir.

*Bu çalışma, 12-13 Ekim 2017 tarihleri arasında Bosna Hersek'te düzenlenen “3rd International Conference on Education, Culture and Identity-ICECI 2017" kongresinde "Students' Knowledge about Sustainable Tourism" başlıklı özet olarak sunulan sözlü bildirinin genişletilmiş halidir.

Anahtar Kelimeler: Sürdürülebilirlik, Sürdürülebilir Turizm, Eğitim, Üniversite Öğrencileri.

Makale Gönderme Tarihi: 22.04.2019

Makale Kabul Tarihi: 06.07.2019

\section{Önerilen Atıf:}

Binbaşığlu, H., Tuna, A., Özer, N. ve Şad, S. N. (2019). Üniversite Öğrencilerinin Sürdürülebilirlik ve Sürdürülebilir Turizm Hakkındaki Bilgi Düzeyleri, Türk Turizm Araştırmaları Dergisi, 3(3): 338-349.

(C) 2019 Türk Turizm Araştırmaları Dergisi. 


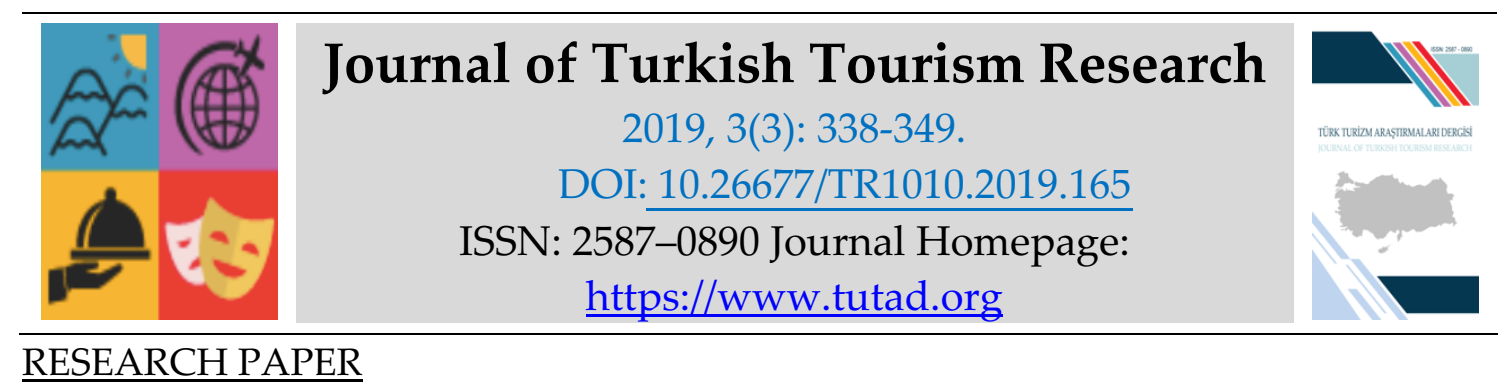

\title{
University Students' Knowledge Level of Sustainability and Sustainable Tourism Concepts
}

Assistant Prof. Dr. Hulusi BİNBAŞIOĞLU, Malatya Turgut Özal University, Kale Tourism and Hotel Management Vocational School, Malatya, e-mail: hulusi.binbasioglu@ozal.edu.tr ORCID: https://orcid.org/0000-0001-7488-8450

Assistant Prof. Dr. Aysun TUNA, İnönü University, Faculty of Design and Fine Arts, Malatya, email: aysun.tuna@inonu.edu.tr. ORCID: https://orcid.org/0000-0001-5365-3273

Associate Prof. Dr. Niyazi ÖZER, İnönü University, Faculty of Education, Malatya, e-mail: niyazi.ozer@inonu.edu.tr. ORCID: https://orcid.org/0000-0001-7745-6645

Prof. Dr. Süleyman Nihat ŞAD, İnönü University, Faculty of Education, Malatya, e-mail: nihat.sad@inonu.edu.tr

ORCID: https://orcid.org/0000-0002-3169-2375

\begin{abstract}
This study aims to measure the level of university students' knowledge about sustainability and sustainable tourism. Descriptive and causal-comparative research designs were used. Descriptive statistics were used to determine how familiar the students are with the related concepts. The analysis of students' knowledge of the related concepts in terms of gender, the chi-square statistic was employed. According to results, it was found that a large majority of students are not familiar with the technical concepts including carbon footprint, ecological footprint, while they are familiar with general concepts related to sustainability such as climate change, recycling, cultural diversity, protection of ecosystems, biodiversity, and waste management. In terms of gender, a significant difference between male and female students' views on poverty reduction, carbon footprints, and ecological footprints was found in favor of male students.
\end{abstract}

Keywords: Sustainability, Sustainable Tourism, Education, University Students.

Received: 22.04 .2019

Accepted: 06.07.2019

\section{Suggested Citation:}

Binbaşığlu, H., Tuna, A., Özer, N. and Şad, S. N. (2019). University Students' Knowledge Level of Sustainability and Sustainable Tourism Concepts, Journal of Turkish Tourism Research, 3(3): 338349.

(c) 2019 Türk Turizm Araştırmaları Dergisi. 


\section{Gíriş}

Kalkınma her ülke için önemli bir konudur. Bu durum, ülkeler arasında büyük çaplı olduğu gibi, yerel anlamda küçük çaplı da gerçekleşebilmektedir. Bir bölgenin gelişmesi için zorunlu olan sürdürülebilir kalkınmanın, ekonomik, sosyal ve çevresel bir anlayışı içermesi gerekmektedir (Koşan, 2006). Küresel anlamda sürdürülebilir kalkınmanın artan önemi, birçok konunun ve kavramın tartışılmasını da beraberinde getirmektedir (Wall, 1997; Beyhan ve Ünügür, 2005; Brandli vd., 2015). Türkiye'deki şehirlerin ekonomik, sosyal ve çevre performanslarıyla birlikte incelendiği sürdürülebilirlik endeksi sonuçlarına göre, Ankara, İstanbul ve İzmir sürdürülebilirlikte en ön sırada yer alırken, bu illeri nispeten daha düşük skorlarla Eskişehir, Kocaeli ve Bursa izlemektedir (MasterCard, 2011). Sürdürülebilir kalkınma hedeflerine en hızlı ulaşabilen ülkeler ise İsveç, Danimarka, Norveç, Finlandiya ve İsviçre olarak sıralanmaktadır (SDG Index, 2017: 10). Dünyada 157 ülkenin yer aldığı bu endekste, Türkiye bu ülkeler içerisinde 67. sirada yer almaktadir.

Sürdürülebilirlik çoğunlukla çevreyle, kalkınma ise ekonomiyle ilişkilendirilen konulardan biridir. Ancak, sürdürülebilir kalkınmanın sadece çevresel ve ekonomik değil, sosyal ayağı da bulunmaktadır (Goodland, 1995). Yakın zamana kadar sürdürülebilir kalkınma, çevresel kaygıların ekonomik karar alma sürecine entegre edilmesi ile ilgili olarak temelde çevresel bir mesele olarak algılanırken, yaşanan küresel ekonomik krizler toplumsal anlamda kalıcı hasarlar bıraktığı için, kalkınmanın toplumsal boyutlarına yönelik araştırmalara olan ilgi de artmıştır (Lehtonen, 2004). Bu boyutların kapsamındaki stratejik konular şu şekilde detaylandırılabilir (UNESCO, 2005: 5):

Sosyal boyut: İnsan hakları, barış ve insan güvenliği, cinsiyet eşitliği, kültürel çeşitlilik ve kültürlerarası anlayış, sağlık, HIV/AIDS, yönetişim.

Ekonomik boyut: Yoksulluğu azaltma, kurumsal sorumluluk ve hesap verebilirlik, pazar ekonomisi.

Çevresel boyut: Doğal kaynaklar (su, enerji, tarım, biyo-çeşitlilik), iklim değiş̧ikliği, kırsal kalkınma, sürdürülebilir kentleşme, afet önleme ve azaltma.

Sürdürülebilirlik kapsamında insanlar kendini, mevcut sistemin bir parçası olarak görerek doğal çevresine saygı duyacak, sosyal ve ekonomik gelişmesini de bu çerçevede sürdürecektir (Berberoğlu ve Uygun, 2013). Doğayı hiçe sayarak gerçekleştirilen bir ekonomik kalkınma anlayışı mevcut çevreyi sürdürülemez hale getirecektir (Keskin, 2012). Sürdürülebilirlik kavramının temelinde taviz vermek veya bir seçim yapmak vardır (Fisk, 2010). Örneğin bir tüketicinin karbon salımı daha düşük olan bir otomobili mi yoksa tüm ailenin sığacağı büyük bir otomobili mi satın alacağı, sürdürülebilirlik ile işlevsellik arasındaki tercihini ortaya koyarken bir özellikten de feragat etmesine sebep olacaktır.

Birleşmiş Milletler (2015) tarafından yayınlanan "Sürdürülebilir Kalkınma için 2030 Ajandası"nda belirtilen on yedi hedeften biri, sürdürülebilir kalkınma için kaliteli bir eğitimin verilmesi gerekliliğidir ve yine en önemli hedeflerden birisi de özellikle gelişmekte olan ülkeler bağlamında, sürdürülebilir kalkınma konusundaki bilinç düzeyinin artırılmasıdır. Bu çalışmanın temel amacı da, üniversite öğrencilerinin sürdürülebilirlik ve sürdürülebilir turizm ile ilgili kavramlara ilişkin bilgi düzeylerini ölçmektir. Literatürde çalışmaların birçoğu öğrencilerin çevresel konulara ilişkin görüşleri (MacDonald ve Hara, 1994; Duerden ve Witt, 2010; Teksöz vd., 2010; Oğuz vd., 2011; Yıldız, 2011; Talas ve Karataş, 2012; Sadık, 2013) üzerine yoğunlaşırken çok az bir kısmı sosyal, ekonomik ve çevresel anlamda bir bütün olarak sürdürülebilirlik ve sürdürülebilir turizm konusu (Kagawa, 2007; Demirbaş, 2015; Camargo ve Gretzel, 2017) üzerinde durmaktadır. Yapılan çalışmalar göz önünde bulundurulduğunda, üniversite 
öğrencilerinin sürdürülebilirlik ve sürdürülebilir turizm hakkındaki bilgi düzeyleri ölçülmesinin bu alanda var olan eksikliği dolduracağı düşünülmektedir.

Çalışmanın literatür kısmında öncelikle sürdürülebilirlik kavramı ile turizm sektörü ilişkisi açıklandıktan sonra, bu alanda yapılan çalışmalara yer verilmiştir. Araştırma uygulama alanı olarak üniversite öğrencileri ele alınmış ve çalışmanın yöntemi açıklanmıştır. Araştırma sonucunda elde edilen bulgular analiz edilerek sonuç ve önerilere yer verilmiştir.

\section{LITERATÜR}

Doğal çevre, sosyal çevre ve ekonomiyle sıkı bir ilişkisi olan turizm sektörü de sürdürülebilirlik noktasında önemli bir görev üstlenmektedir. Çünkü turizm faaliyetlerinin gerçekleştiği bütün alanlar, doğal çevre ve sosyal çevreyle iç içedir. Ayrıca yürütülen turizm faaliyetlerinin birçoğu ekonomik anlamda kazanç elde etmek için yapılmaktadır. Sürdürülebilir turizm ile ilgili olarak birçok konu önem arz etmektedir. Bu konuların başlıcaları şöyle sıralanabilir: İklim değişikliği, geri dönüşüm, kültürel çeşitlilik, etik ve davranış kuralları, ekosistemler ve biyo-çeşitliliğin korunması, atık yönetimi, sera gazları, karbon ayak izi, sürdürülebilir kalkınma, ekolojik ayak izi, adil ticaret, sürdürülebilir turizm göstergeleri, sürdürülebilir turizm sertifikası, katılımcı planlama, paydaş katılımı.

İklim değişikliği turizm sektörünün geleceği açısından önemli bir konudur. Bu konuda yapılan araştırmalar genel olarak üç ana alana odaklanmaktadır (Hall, 2011): Turizm ile ilgili faaliyetlerin emisyonları ve iklim değişikliğine katkılarının neler olduğu, iklim değişikliğinin turizm üzerindeki etkilerinin neler olduğu ve iklim değişikliğinin etkilerinin nasıl hafifletilebileceğidir. Turizmde atık yönetimi ve geri dönüşüm faaliyetleri, konaklama işletmeleri başta olmak üzere yiyecek-içecek, ulaştırma gibi işletmelerde hizmetlerin yürütülmesi sırasında ortaya çıkan atıklar, bu atıkların uygun bir şekilde toplanması ve değerlendirilmesi olarak tanımlanmaktadır (Deste vd., 2018). Yoğun turizm faaliyetlerinin hassas ekosistem ve biyo-çeşitliliğe sahip alanlarında gerçekleşmesi nedeniyle, bu alanların geleceğini tehdit ederek, faaliyetlerin sürdürülebilirliğini zorlaştırmaktadır (Başarangil ve Tokatlı, 2016). Sürdürülebilir turizm açısından sera gazı ve karbon ayak izinin önemi, başta havayolu olmak üzere diğer ulaştırma araçları ile ve konaklama işletmelerinin ısınma ve soğutma gibi faaliyetlerinde kullandığı enerjinin ciddi bir sera gazı ve karbon ayak izi bırakmasından ileri gelmektedir (Tuna ve Özdemir, 2016). Ayrıca toplumları ilgilendiren sosyal ve kültürel çeşitliliğin korunması, desteklenmesi ve sürdürülebilir uygulamalar konusunda ilgili paydaşların eğitilmesi sürdürülebilir turizm konusunda ele alınması gereken önemli hususlardan biridir (Sloan vd., 2009). Turizmde adil ticaret ise, küçük çaplı firmaların bir araya gelerek, büyük çaplı uluslararası havayolları, oteller ve benzeri turizm şirketlerinin güçlü pazar hâkimiyetini kırmanın yollarından biri olarak ifade edilmektedir (Hjalager, 2010). Bununla birlikte, bilinçli bir sürdürülebilir turizmi teşvik etmek ve ihtilaflara çözüm bulmak için kamuoyunun, bu konular hakkında yeterince bilinçli olmaları ve bunun yanı sıra bütün paydaşların katılımı sağlanarak katılımcı planlama ve fikir birliği oluşturmak bu sürecin önemli bir adımıdır (Dwyer ve Edwards, 2010).

Yaklaşık yedi milyar insanın yaşadığı bir dünyada, sınırlı doğal kaynaklarla bireyler ve toplumlar sürdürülebilir şekilde birlikte yaşamayı öğrenmelidirler (UNESCO, 2017). İlk defa 1992 yılında Rio de Janerio'da düzenlenen Birleşmiş Milletler Dünya Çevre ve Kalkınma Konferansında ele alınan bir kavram olan (UNESCO, 2005) sürdürülebilir kalkınmanın güçlüklerinden birisi de sürdürülebilirliğin uygulama sürecidir (Alghamdi, 2018). Sürecin herhangi bir aşamasında yaşanabilecek bir eksiklik hedeflere ve amaçlara ulaşmada sıkıntıya yol açacaktır (Ayyıldız ve Genç, 2008). Bu sürecin iyi kavranması ve yönetilmesi başarıyı getirecektir. 
Günümüzde sürdürülebilirlik konusunun öneminin daha iyi anlaşıldığı ve yürütülen her faaliyetin sürdürülebilir nitelikte olmasının öneminin daha iyi kavrandığı görülmektedir (Türk, 2010). Yetişmiş insan gücünü hazırlayan bir araç olması nedeniyle eğitim, bir ülkenin sürdürülebilir kalkınmasını sağlamada oldukça önemli bir role sahiptir (Gedikoğlu, 2005; Alkış, 2007; Kaya ve Tomal, 2011; Demirbaş, 2015). Her alanda sürdürülebilir bir kalkınmanın sağlanabilmesi için uluslararası standartlara uygun bir eğitimin verilmesi gereklidir (Kınsız, 2005). Verilen eğitimler, insanları sürdürülebilir bir gelecek için düşünmeye ve çalışmaya zorlamaktadır (UNESCO, 2017).

Sürdürülebilirlik konusunun tam merkezinde işletmeler, resmi kurumlar veya çevreciler değil, her geçen gün daha da artan bir bilinçle düşünen ve hareket eden tüketiciler bulunmaktadır (Fisk, 2010). Sürdürülebilir turizm faaliyetleri, sadece belli kurumların sorumluluğunda olmayıp, turizm hareketliliğine katılan yerli ve yabancı turistlerin de sorumlulukları bulunmaktadır. Bu noktada, sürdürülebilir turizm ile ilgili kararlar alınırken, ilgili bütün paydaşların düşüncelerinin alınması çok önemlidir (Korkmaz ve Başkalkan, 2011). Özellikle üniversite öğrencisi olan gençlerin de sürdürülebilirlik konusuna duyarlılığı uzun yıllardır mevcuttur (Cini vd., 2015; Camargo ve Gretzel, 2017). Öğrenciler, sosyal sorumluluk ve satın alma davranışları (Ayyıldız ve Genç, 2008; Aslan ve Çınar, 2015) dahil olmak üzere birçok konuda sürdürülebilirliğe duyarlı davranışlar sergilemektedir. Bununla birlikte şirketlerden ve yerel yönetimlerden de bu tür uygulamaları talep etmektedir. Sürdürülebilir bir gelecek için öğrencilerin üstleneceği rol, bu noktada çok önemlidir. Çünkü bir tüketici olarak gençler değişirse kurum ve kuruluşlar da değişir (WEF, 2009). Sürdürülebilir kalkınma için verilecek olan eğitimlerde kamusal bilgi düzeyi ve farkındalığı artırmak amacıyla, her ne kadar bu kavram kurumsal ve akademik çevrede bilinir olsa da sürdürülebilir kalkınma kavramının tabana yayılmasına ihtiyaç duyulmaktadır ve bu nedenle de iş dünyasından en uzak bölgelerdeki çocuklara kadar bütün toplum kesimleri hedef alınmalıdır (UNESCO, 2005). Verilecek sürdürülebilirlik ve sürdürülebilir turizm eğitimiyle öğrenciler, yaşadığı topluma ve doğaya zarar vermeden, ekonomik kazanımlar elde edebilmenin yöntemlerini öğrenmiş olacaklardır. Sürdürülebilirlik ile elde edilen kazanımların nihai hedeflerinden birisi de, ekonomik ve sosyal sorunların çözümüne aktif olarak katılabilen, çevreye duyarlı, sürdürülebilir kalkınmayı kavramış ve benimsemiş, dünya ile uyumlu bir vatandaş oluşturmaktır (Hsu, 2004; Atasoy ve Ertürk, 2008). Öyle ki, sürdürülebilir kalkınma için gerekli olan eğitimin amaçları ile bu kapsamda toplumun bireylerinin sahip olması gereken yetkinlik, bilgi, beceri ve davranış gibi özellikler de birbiriyle örtüşmektedir (Kaya ve Tomal, 2011). Bu noktada eklenebilecek bir diğer önemli husus ise, bu eğitimle üniversitelerden mezun olacak öğrencilerin, iş yaşamında kendilerine katkı sağlayacak sürdürülebilirlik ve sürdürülebilir turizm ile ilgili kavramlara hâkim ve bunları yönetebilecek beceriye sahip olmasının sağlanabilmesidir (Jamal vd., 2011).

Özel sektör ve resmi kurumlarla birlikte bir paydaş olarak sürdürülebilirlik konusuna halkın bakış açısı çok önemlidir. Çünkü sürdürülebilir bir kalkınma ancak sürdürülebilir bir yaşam ilkesini benimseyen kişilerle mümkün olmaktadır (Kaya, 2013). Bu bakış açısını belirleme adına bu çalışmada, üniversite öğrencilerinin sürdürülebilirlik ile ilgili kavramlara ilişkin bilgi düzeylerinin ölçülmesi amaçlanmaktadır. Ülkemizde özellikle çevresel, sosyal ve ekonomik hususları kapsayan sürdürülebilir bir kalkınmanın eksikliği mevcuttur (Yıldız, 2011). Mevcut kaynakların gelecek nesillere aktarılması noktasında, bu sürecin eğitimle bilinçlendirilmesi gerekmektedir. Çünkü sürdürülebilir kalkınmanın gerçekleştirilebilmesi için gerekli olan hususların en başında eğitim gelmektedir (Demirkaya, 2006; Teksöz vd., 2010). Sürdürülebilirlik kavramının ne olduğu ve nasıl uygulanabileceği ancak eğitim ile öğrencilere kazandırılabilir (Yıldız, 2011). Öğrencilerin duyarlılıkları sürdürülebilir turizm faaliyetlerine yönelmelerini sağlayacaktır. Buna bağlı olarak, sürdürülebilir turizm kapsamında sunulan faaliyetlerden 
gençlerin yararlanabilmesi için, gençlerin bu bilince sahip olması gerekmektedir. Bu bilince, üniversite yıllarında ve hatta daha erken dönemlerde sahip olunması çok önemlidir. Hedef kitle olan gençlerin turizm faaliyetlerine katılımlarında sürdürülebilirlik ile ilgili davranışlarını teşvik etmek için onların bu konuyu ne kadar bildiklerini ve hangi bilgi türünün gerekli olduğunu saptamak önem arz etmektedir (Frick vd., 2004). Eğitim, doğal ve kültürel mirasın keşfedilmesinin yanı sıra, onların korunmasına yönelik bir ilgiyi de tetikleyeceğinden, sürdürülebilir turizm ile ilgili konuların da eğitim programlarıyla bütünleştirilmesinde fayda vardır (European Commission, 2007). Böylece, önemli bir paydaş olan gençlerin, sürdürülebilirlik ve sürdürülebilir turizm noktasında hangi bilgiye sahip olduğu ve bunlara ne kadar hâkim olduğu, çalışmanın amacını ortaya koymaktadır.

\section{YÖNTEM}

\section{Desen}

$\mathrm{Bu}$ çalışmanın temel amac1, üniversite öğrencilerinin sürdürülebilirlik ve sürdürülebilir turizm ile ilgili kavramlara ilişkin bilgi düzeylerini ölçmektir. Bu amaca ulaşmak üzere tasarlanan bu araştırmada nicel araştırma geleneğine uygun olarak betimsel ve nedensel karşılaştırmalı desen bir arada kullanılmıştır. Betimsel çalışmalar bir araştırma evreninin eğilim, tutum ya da görüşlerini bu evrendeki bir örneklemle çalışarak nicel ya da sayısal olarak tanımlamaya imkân sağlar (Creswell, 2013). Nedensel karşılaştırmalı araştırmalar ise incelenen değişken iki veya daha fazla alt gruba ayrıldığı için gruplar arasında karşılaştırma yapmaya da fırsat verir (Sözbilir, 2014). Bu araştırmada da önce üniversite öğrencilerinin sürdürülebilirlik ve sürdürülebilir turizm ile ilgili kavramlara ne düzeyde aşina oldukları betimlenmeye çalışılmış, daha sonra ise öğrencilerin ilgili kavramlara aşinalık düzeylerinin cinsiyet değişkenine göre anlamlı farklılık gösterip göstermediği belirlenmeye çalışılmıştır.

\section{Çalışma Grubu}

Araştırmanın çalışma grubunu İnönü Üniversitesi Eğitim Fakültesi ve Güzel Sanatlar Fakültesinde 2017-2018 eğitim-öğretim yılı güz yarıyılında öğrenim gören ve araştırmaya gönüllü olarak katılan toplam 312 öğrenci oluşturmaktadır. Bu fakültelerin araştırma kapsamına alınmasının temel nedeni, bu fakültelerde öğrenim gören öğrencilerin çevre ve çevre duyarlığ 1 konularında eğitim verilmesidir. Bu durum, sürdürülebilirlik ve sürdürülebilir turizm ile ilgili tutum ve davranış değişikliği konusunda etkili olabilmektedir. Ayrıca çalışmanın yazarlarından bazılarının bu fakültelerde görev yapması, katılımcılara ulaşma ve gönüllü katılım açısından kolaylık sağlamıştır. Bu nedenle bu iki fakültede öğrenim gören öğrencilerin araştırma kapsamına alınmasına karar verilmiştir. Yapılan uygulama sonucunda eksik ve hatalı doldurulan veri toplama araçları ayıklanmıştır. Eksik ve hatalı doldurulan 22 veri toplama aracının çıkarılmasından sonra toplam 290 öğrenciden toplanan veri değerlendirilmeye alınmıştır. Araştırmanın çalışma grubunu oluşturan bu katılımcıların 207'si kadın, 83'ü ise erkektir. Katılımcların sinıf düzeylerine göre dağılımı ise; 1 . sınıf 62, 2. sınıf 60, 3. sınıf 86 ve 4. sinıf 82 kişi olarak gerçekleşmiştir.

\section{Veri Toplama Araçları}

Araştırmada Camargo ve Gretzel (2017) tarafından geliştirilen 17 sorudan oluşan anket formu kullanılmıştır. Bu sorulara ek olarak "geri dönüşüm, atık yönetimi ve ekolojik ayak izi" ile ilgili üç soru da ankete eklenmiştir. Anket formunda demografik değişkenler dışında toplam 20 madde yer almaktadır. Anket formu öğrencilerin sosyal, ekonomik ve çevresel anlamda bir bütün olarak sürdürülebilirlik konusundaki görüşlerini değerlendirmek üzere tasarlanmıştır. Anket formundaki sorular aracılı̆̆ıyla öğrencilerin sürdürülebilirlikle ilgili belirli ilke ve mekanizmalara ve bilgi kaynaklarına aşinalıklarını değerlendirmeleri istenmiştir. Formda iklim 
değişikliği, geri dönüşüm, kültürel çeşitlilik, atık yönetimi, sera gazları, karbon ayak izi gibi sürdürebilirlikle ilgili konularda öğrencilerin görüş belirtmeleri istenmiştir. Anket formu araştırmacılar tarafından Türkçe'ye çevrilmiştir.

\section{Verilerin Analizi}

Üniversite öğrencilerinden elde edilen veriler analiz edilmeden önce hatalı ve eksik veri olup olmadığı incelenmiştir. Daha sonra verilerin normal dağılım sergileyip sergilemediğini belirlemek üzere basıklık ve çarpıklık değerleri ile dağılım grafikleri incelenmiştir. Her bir maddeye ilişkin basıklık ve çarpıklık değerlerinin \pm 1 aralığında olduğu belirlendiğinden verilerin normal dağılım sergilediği kabul edilmiştir (Can, 2014). Öğrencilerin sürdürülebilirlik ile ilgili kavramlara ne düzeyde aşina olduklarını belirlemek üzere elde edilen veriler üzerinden betimsel istatistik (yüzde, frekans) hesaplamaları yapılmıştır. Öğrencilerin sürdürülebilirlik ile ilgili kavramlara ilişkin aşinalık düzeylerinin cinsiyet değişkeni açısından analizinde ise, veriler normal dağılım gösterse bile veri toplama aracı ölçek değil de anket olduğundan kay kare istatistiği kullanılmıştır.

\section{BULGULAR VE YORUM}

Araştırmada öncelikli olarak üniversite öğrencilerinin sürdürülebilirlik ile ilgili kavramlara ne düzeyde aşina oldukları belirlenmek istenmiştir. Bu amaçla elde edilen veriler üzerinden yapılan betimsel istatistik sonuçları Tablo 1'de verilmiştir.

Tablo 1. Katılımcıların Sürdürülebilirlikle İlgili Kavramlara İlişkin Aşinalık Düzeyleri

\begin{tabular}{|c|c|c|c|c|c|c|c|c|c|c|}
\hline & \multicolumn{2}{|c|}{$\begin{array}{c}\text { Hiç Tanıdık } \\
\text { Değil }\end{array}$} & \multicolumn{2}{|c|}{ Az Tanıdık } & \multicolumn{2}{|c|}{$\begin{array}{l}\text { Kismen } \\
\text { Tanıdik }\end{array}$} & \multicolumn{2}{|c|}{$\begin{array}{l}\text { Oldukça } \\
\text { Tanıdık }\end{array}$} & \multicolumn{2}{|c|}{$\begin{array}{c}\text { Tamamen } \\
\text { Tanidık }\end{array}$} \\
\hline & $\mathrm{f}$ & $\%$ & $\mathrm{f}$ & $\%$ & $\mathrm{f}$ & $\%$ & $\mathrm{f}$ & $\%$ & $\mathrm{f}$ & $\%$ \\
\hline İklim değişikliği & 4 & 1,4 & 7 & 2,4 & 27 & 9,3 & 71 & 24,5 & 181 & 62,4 \\
\hline Geri dönüşüm & 5 & 1,7 & 7 & 2,4 & 31 & 10,7 & 69 & 23,8 & 178 & 61,4 \\
\hline Kültürel çeşitlilik & 1 & 0,3 & 15 & 5,2 & 60 & 20,7 & 67 & 23,1 & 147 & 50,7 \\
\hline Etik ve davranış kuralları & 8 & 2,8 & 20 & 6,9 & 62 & 21,4 & 90 & 31,0 & 110 & 37,9 \\
\hline Ekosistemler ve biyo-çeşitliliğin korunması & 11 & 3,8 & 27 & 9,3 & 70 & 24,1 & 74 & 25,5 & 108 & 37,2 \\
\hline Atık yönetimi & 22 & 7,6 & 28 & 9,7 & 67 & 23,1 & 69 & 23,8 & 104 & 35,9 \\
\hline Sosyal eşitlik & 10 & 3,4 & 37 & 12,8 & 72 & 24,8 & 79 & 27,2 & 92 & 31,7 \\
\hline Yoksulluğu azaltma & 16 & 5,5 & 32 & 11,0 & 70 & 24,1 & 88 & 30,3 & 84 & 29,0 \\
\hline Sera gazları & 31 & 10,7 & 33 & 11,4 & 84 & 29,0 & 71 & 24,5 & 71 & 24,5 \\
\hline Taşıma kapasitesi & 44 & 15,2 & 56 & 19,3 & 82 & 28,3 & 55 & 19,0 & 53 & 18,3 \\
\hline Karbon ayak izi & 96 & 33,1 & 54 & 18,6 & 57 & 19,7 & 33 & 11,4 & 50 & 17,2 \\
\hline Sürdürülebilir kalkınma & 40 & 13,8 & 73 & 25,2 & 86 & 29,7 & 42 & 14,5 & 49 & 16,9 \\
\hline Nesiller arası eşitlik & 48 & 16,6 & 58 & 20,0 & 78 & 26,9 & 60 & 20,7 & 46 & 15,9 \\
\hline Ekolojik ayak izi & 89 & 30,7 & 62 & 21,4 & 57 & 19,7 & 42 & 14,5 & 40 & 13,8 \\
\hline Adil ticaret & 69 & 23,8 & 72 & 24,8 & 82 & 28,3 & 35 & 12,1 & 32 & 11,0 \\
\hline Sürdürülebilir turizm göstergeleri & 45 & 15,5 & 89 & 30,7 & 83 & 28,6 & 49 & 16,9 & 24 & 8,3 \\
\hline Sürdürülebilir turizm sertifikası & 95 & 32,8 & 79 & 27,2 & 67 & 23,1 & 29 & 10,0 & 20 & 6,9 \\
\hline Çevre sertifikasyon programları & 97 & 33,4 & 89 & 30,7 & 51 & 17,6 & 34 & 11,7 & 19 & 6,6 \\
\hline Katılımcı planlama & 83 & 28,6 & 78 & 26,9 & 77 & 26,6 & 33 & 11,4 & 19 & 6,6 \\
\hline Paydaş katılımı & 130 & 44,8 & 72 & 24,8 & 55 & 19,0 & 21 & 7,2 & 12 & 4,1 \\
\hline
\end{tabular}

Tablodaki bulgular incelendiğinde araştırmaya katılan üniversite öğrencilerinin büyük bir çoğunluğunun iklim değişikliği, geri dönüşüm, kültürel çeşitlilik, ekosistemler ve biyoçeşitliliğin korunması, atık yönetimi gibi sürdürülebilirlikle ilgili temel kavramlara çoğunlukla 
aşina oldukları, buna karşın karbon ayak izi, ekolojik ayak izi gibi uygulamalı ve teknik konulara pek aşina olmadıkları görülmektedir. Özellikle günlük hayatta çok karşılaşılan kavramlar olduğu için, öğrenciler iklim değişikliği, atık yönetimi gibi konulara daha aşina olabilirler. Eğer özel olarak bir derste bu konuları işlemediler veya üzerinde bir çalışma yapmadılarsa paydaş katılımı, sertifikasyon programları, karbon ayak izi ve ekolojik ayak izi gibi daha teknik konulara öğrencilerin aşina olmamaları normal bir durum olarak değerlendirilebilir.

Katılımcların sürdürülebilirlik ile ilgili kavramlara ilişkin aşinalık düzeylerinin cinsiyet değişkenine göre anlamlı farklılık gösterip göstermediğini belirlemek üzere kay kare analizi yapılmıştır. Yapılan kay kare analizi sonucunda öğrencilerin sadece yoksulluğu azaltma $\left(\mathrm{X}^{2}=\right.$ 2.556, $\mathrm{p}=.01)$, karbon ayak izi $\left(\mathrm{X}^{2}=2.241, \mathrm{p}=.03\right)$ ve ekolojik ayak izi $\left(\mathrm{X}^{2}=3.843, \mathrm{p}=.00\right)$ konularındaki aşinalıkları arasında anlamlı farklılık olduğu belirlenmiştir. Her üç konuda da erkek öğrencilerin kadın öğrencilere göre bu konularda kendilerini daha yetkin hissettikleri belirlenmiştir.

\section{TARTIŞMA, SONUÇ VE ÖNERILER}

UNESCO (1997) tarafından hazırlanan "Sürdürülebilir Gelecek İçin Eğitim" programında sürdürülebilir bir ekonomik kalkınma için, ülkelerin sahip oldukları doğal kaynakları etkili ve verimli kullanması gerektiği belirtilmektedir. Ekonomik anlamda ülkelere oldukça önemli bir katkı sunan turizm sektörünün devamlılığını sağlayabilmesi, kaynakların sürdürülebilir kullanılmasıyla sağlanabilir. Kaynakların etkili kullanılması ise ancak sürdürülebilirlik konusunda bilgi, beceri ve tutum sahibi bireylerin yetiştirilmesi ile mümkündür. Ayrıca turistik alanların çekiciliğinin artırılması için de mevcut kaynakların sürdürülebilirlik stratejisi içerisinde planlanması gerekmektedir (Çetin vd., 2017) ve stratejik olarak yürütülen sürdürülebilir turizm bölgeleri, günümüz rekabet ortamında destinasyonlara ve işletmelere avantaj sağlamaktadır (Nkemngu, 2017). Aksi takdirde, düzgün bir şekilde planlanmamış ve yönetilmeyen turizm faaliyetleri, destinasyonların fiziksel, sosyo-kültürel ve ekonomik ortamlarında kalıcı zararlar bırakabilmektedir (Dwyer ve Edwards, 2010). Bu nedenle ekonomik kalkınma ve toplumsal refahın sağlanması için sürdürülebilirlik ve sürdürülebilir turizm ile ilgili kavram ve ilkelerin okul öncesinden yükseköğretime kadar her tür ve düzeyde verilen eğitim aracıllğ̆ıla topluma kazandırılması gerekmektedir.

$\mathrm{Bu}$ araştırma ile öncelikli olarak üniversite öğrencilerinin sürdürülebilirlik ve sürdürülebilir turizmle ilgili temel kavramlara ne düzeyde aşina oldukları belirlenmek istenmiştir. Yapılan analizler sonucunda öğrencilerin büyük bir çoğunluğunun iklim değişikliği, geri dönüşüm, kültürel çeşitlilik, ekosistemler ve biyo-çeşitliliğin korunması, atık yönetimi gibi sürdürülebilirlikle ilgili genel kavramlara aşina oldukları buna karşın karbon ayak izi, ekolojik ayak izi gibi teknik ve uygulamaya dönük kavramlara ise çok aşina olmadıkları belirlenmiştir. Benzer bulgular, Camargo ve Gretzel (2017) tarafından yapılan çalışmada da ortaya çıkmıştır. Çalışmada üniversite öğrencilerinin en çok aşina olduğu konular sırasıyla iklim değişikliğ̈i, kültürel çeşitlilik, yoksulluğu azaltma, etik ve davranış kuralları, ekosistemler ve biyo-çeşitliliğin korunması ile sosyal eşitlik olmuştur. Mevcut çalışmaya sonradan eklenen geri dönüşüm ve atık yönetimi soruları çıkartıldığında, Camargo ve Gretzel (2017) tarafından yapılan çalışmayla, mevcut çalışmanın öğrencilerin en çok aşina olduğu konularının aynı olduğu görülmektedir. En az aşina olduğu konular da benzer bir şekilde, nesiller arası eşitlik, karbon ayak izi, paydaş katılımı, adil ticaret ve sürdürülebilir turizm sertifikası olarak sıralanmaktadır. Bu bulgular öğrencilerin sürdürülebilirlikle ilgili pek çok kavrama ilişkin sınırlı bilgilere sahip olduklarını ve sahip oldukları bilginin çoğunun da sürdürülebilirliğin daha çok çevre boyutu ile ilgili olduğunu göstermektedir. Benzer bir şekilde, Kagawa (2007) tarafından yapılan başka bir araştırmada da sürdürülebilirliği iyi bir şey olarak değerlendiren öğrenciler, bu konuyu büyük çoğunlukla 
çevreyle ilişkilendirmektedirler. Yine başka bir çalışmada (Demirbaş, 2015) ise, eğitim fakültesi öğrencilerinin sürdürülebilir kalkınma farkındalık düzeyleri çevresel etik faktöründe yüksek düzeyde çıkmıştır. Oysa sürdürülebilirlik ekonomik, sosyal ve politik boyutları da olan geniş bir kavramdir.

Cinsiyet değişkeni açısından yapılan analizlerde ise yoksulluğu azaltma, karbon ayak izi ve ekolojik ayak izi konularında kadın ve erkek öğrencilerin görüşleri arasında anlamlı farklılıklar olduğu, erkek öğrencilerin kendilerini bu kavramlara daha aşina algıladıkları belirlenmiştir. Camargo ve Gretzel (2017) tarafından yapılan çalışmada ise, sürdürülebilir kalkınma, sosyal eşitlik ve adil ticaret konularında erkek öğrenciler lehine anlamlı bir farklılık bulunmaktadır. Başka bir araştırmada ise (Kagawa, 2007) benzer bir şekilde, erkek üniversite öğrencilerinin, kadın öğrencilere nazaran sürdürülebilirlik ve sürdürülebilir kalkınmaya karşı aşinalıklarının daha fazla olduğu vurgulanmıştır. Buna karşın, Demirbaş (2015) tarafından öğretmen adaylarının sürdürülebilir kalkınma farkındalık düzeylerinin araştırıldığı çalışmada, öğrencilerin cinsiyetleri ile sürdürülebilir kalkınma farkındalıkları arasında anlamlı bir farklılık bulunamamıştır.

Özellikle, verilecek olan eğitimlerde çevresel, sosyal ve ekonomik konulara da yer vererek güncel yaklaşımların takip edilmesi sağlanabilir (Demirkaya, 2006). Yaptıkları araştırmada Camargo ve Gretzel (2017), üniversite öğrencilerinin sürdürülebilirlikle ilgili bilgilere üniversitede aldıkları dersler $(\% 90)$, internet $(\% 65,5)$, basılı medya (kitap, gazete, dergi) $(\% 49,1)$, seminer, çalıştay veya konferanslar $(\% 37,4)$, televizyon veya radyo $(\% 36,3)$ ile çalışma ortamı $(\% 18,7)$ vasıtasıyla ulaştıklarını belirtmişlerdir. Bu bulgularda da görüldüğü gibi, öğrencilerin sürdürülebilirlik ve sürdürülebilir kalkınmayla ilgili en önemli bilgi kaynağı üniversitede aldıkları derslerdir. Bununla birlikte, sürdürülebilir kalkınma için evrensel bir eğitim formülü bulunmamasına rağmen, hızla değissen dünyaya ayak uydurmak için, böyle özellikli konularda müfredatlarını öğrencilerin ilgi, istek ve ihtiyaçlarına göre düzenlenmede yükseköğretim kurumlarına çok büyük görev düşmektedir (Kagawa, 2007). Verilecek eğitimlerde çevresel konularla birlikte ekonomik ve sosyal konuların da ön plana çıkarılması, sürdürülebilir kalkınmanın anlaşılmasını ve sürdürülebilir turizm faaliyetlerine katkıda bulunmalarını kolaylaştırabilir. Üniversitelerde eğitim başta olmak üzere, birçok bölümde sürdürülebilirlik ile ilgili seçmeli dersler müfredata eklenebilir. İleride yapılacak çalışmalarda, sadece turizm bölümü öğrencilerine yönelik bir araştırma yapılabilir. Ayrıca, sürdürülebilirlikle ilgili bilgi kaynaklarının ne olduğu değişkenlere eklenebilir.

\section{KAYNAKÇA}

Alghamdi, N. (2018). Knowledge and Awareness of Sustainability in Saudi Arabian Public Universities, (Editör) Leal Filho, W.: Handbook of Sustainability Science and Research içinde (ss.103127), New York: Springer.

Alkış, S. (2007). Coğrafya Eğitiminde Yükselen Paradigma: Sürdürülebilir Bir Dünya, Marmara Coğrafya Dergisi, 15: 55-64.

Aslan, F. ve Çınar, R. (2015). Yeşil Pazarlama Faaliyetleri Çerçevesinde Kafkas Üniversitesi Öğrencilerinin Çevreye Duyarlı Ürünleri Kullanma Eğilimlerini Belirlemeye Yönelik Bir Araştırma, KAÜ İ̈BF Dergisi, 6(9): 169-184.

Atasoy, E. ve Ertürk, H. (2008). İlköğretim Öğrencilerinin Çevresel Tutum ve Çevre Bilgisi Üzerine Bir Alan Araştırması, Erzincan Eğitim Fakültesi Dergisi, 10(1): 105-122. 
Ayyıldız, H. ve Genç, K.T. (2008). Çevreye Duyarlı Pazarlama: Üniversite Öğrencilerinin Çevreye Duyarlı Pazarlama Uygulamaları İle İlgili Tutum ve Davranışları Üzerine Bir Araştırma, Atatürk Üniversitesi Sosyal Bilimler Enstitüsü Dergisi, 12(2): 505-527.

Başarangil, İ. ve Tokatlı, C. (2016). Botanik Bahçelerinde Sürdürülebilir Yönetim İlkeleri: Örnek Botanik Bahçeleri, II. Ulusal Sürdürülebilir Turizm Kongresi, Akdeniz Üniversitesi 28-30 Nisan 2016. Antalya.

Berberoğlu, E.O. ve Uygun, S. (2013). TÜBİTAK 4004 Projelerinin 'Sürdürülebilir Kalkınma İçin Çevre Eğitimi' Kapsamında Değerlendirilmesi, Abant İzzet Baysal Üniversitesi Eğitim Fakültesi Dergisi, 13(2): 107-133.

Beyhan, Ş.G. ve Ünügür, S.M. (2005). Çağdaş Gereksinmeler Bağlamında Sürdürülebilir Turizm ve Kimlik Modeli, İTü Dergisi/A Mimarlık, Planlama, Tasarm, 4(2): 79-87.

Birleşmiş Milletler (2015). Transforming Our World: The 2030 Agenda for Sustainable Development. [Online] https://sustainabledevelopment.un.org/post2015/transformingourworld/publication [Erişim Tarihi: 08.09.2018].

Brandli, L.L., Leal Fillho, W., Frandoloso, M.A.L., Korf, E. and Daris, D. (2015). The Environmental Sustainability of Brazilian Universities: Barriers and Pre-conditions, (Editör) Leal Filho, W., Azeiro, U.M., Caeiro S. ve Alves, F.: Integrating Sustainability Thinking in Science and Engineering Curricula içinde (ss.63-74) New York: Springer.

Camargo, B.A. and Gretzel, U. (2017). What do Tourism Students Know about Sustainability and Sustainable Tourism? An Exploratory Study of Latin American Students, Journal of Teaching in Travel \& Tourism, 17(2): 101-117.

Can, A. (2014). SPSS ile Bilimsel Araştırma Sürecinde Nicel Veri Analizi, Ankara: Pegem Akademi.

Cini, F., Van der Merwe, P. and Saayman, M. (2015). Tourism Students' Knowledge and Tenets towards Ecotourism, Journal of Teaching in Travel \& Tourism, 15(1): 74-91.

Creswell, J. (2013). Araştırma Deseni: Nitel, Nicel ve Karma Yöntem Yaklaşımları. (Çeviren, Demir, S. B.) Ankara: Eğiten Kitap.

Çetin, İ., Üzümcü, T.P. ve İçöz, O. (2017). Kırsal Alanlarda Sürdürülebilir Kırsal Turizm ve Kocaeli-Kandıra Kırsal Turizm Gelişimi Modeli, Erzincan Üniversitesi Sosyal Bilimler Enstitüsü Dergisi, ÖS-IV: 137-156.

Demirbaş, Ç.Ö. (2015). Öğretmen Adaylarının Sürdürülebilir Kalkınma Farkındalık Düzeyleri, Marmara Coğrafya Dergisi, 31: 300-316.

Demirkaya, H. (2006). Çevre Eğitiminin Türkiye'deki Coğrafya Programları İçerisindeki Yeri ve Çevre Eğitimine Yönelik Yeni Yaklaşımlar, Fırat Üniversitesi Sosyal Bilimler Dergisi, 16(1): 207-222.

Deste, M., Binbaşığlu, H. ve Türk, M. (2018). Konaklama İşletmelerinde Atık Yönetimi ve Geri Dönüşüm: İnönü Üniversitesi Kale Göl Otel Örneği, Anemon Muş Alparslan Üniversitesi Sosyal Bilimler Dergisi, 6(2): 225-234.

Duerden, M.D. and Witt, P.A. (2010). The Impact of Direct and Indirect Experiences on the Development of Environmental Knowledge, Attitudes, and Behavior, Journal of Environmental Psychology, 30: 379-392.

Dwyer, L. and Edwards, D. (2010). Sustainable Tourism Planning, (Editör) Liburd, J.J. ve Edwards, D.: Understanding the Sustainable Development of Tourism, içinde (ss.19-44) Oxford: Goodfellow Publishers Limited. 
European Commission (2007). Action for More Sustainable European Tourism-Report of the Tourism Sustainability

Group.

[Online]

https://ec.europa.eu/docsroom/documents/3683/attachments/1/translations/en/renditions/native [Erişim Tarihi: 18.09.2018].

Fisk, P. (2010). Sürdürülebilir Büyüme. (Çeviren, Yıldırım, E.) İstanbul: MediaCat.

Frick, J., Kaiser, F.G. and Wilson, M. (2004). Environmental Knowledge and Conservation Behavior: Exploring Prevalence and Structure in a Representative Sample, Personality and Individual Differences, 37(8): 1597-1613.

Gedikoğlu, T. (2005). Avrupa Birliği Sürecinde Türk Eğitim Sistemi: Sorunlar ve Çözüm Önerileri, Mersin Üniversitesi Ĕ̆itim Fakültesi Dergisi, 1(1): 66-80.

Goodland, R. (1995). The Concept of Environmental Sustainability, Annual Review of Ecology and Systematics, 26: 1-24.

Hall, C.M. (2011). Climate Change and its Impacts on Tourism: Regional Assessments, Knowledge Gaps and Issues, (Editör) Jones, A. ve Phillips, M.: Disappearing Destinations: Climate Change and Future Challenges for Coastal Tourism içinde (ss.10-29) UK: CAB International.

Hjalager, A.-M. (2010). Supplier-driven Innovations for Sustainable Tourism, (Editör) Liburd, J.J. ve Edwards, D.: Understanding the Sustainable Development of Tourism içinde (ss.148-162) Oxford: Goodfellow Publishers Limited.

Hsu, S.-J. (2004). The Effects of an Environmental Education Program on Responsible Environmental Behavior and Associated Environmental Literacy Variables in Taiwanese College Students, The Journal of Environmental Education, 35(2): 37-48.

Jamal, T., Taillon, J. and Dredge, D. (2011). Sustainable Tourism Pedagogy and Academiccommunity Collaboration: A Progressive Service-learning Approach, Tourism and Hospitality Research, 11(2): 133-147.

Kagawa, F. (2007). Dissonance in Students' Perceptions of Sustainable Development and Sustainability: Implications for Curriculum Change, International Journal of Sustainability in Higher Education, 8(3): 317-338.

Kaya, M.F. (2013). Sürdürülebilir Kalkınmaya Yönelik Tutum Ölçeği Geliştirme Çalışması, Marmara Coğrafya Dergisi, 28: 175-193.

Kaya, M.F. ve Tomal, N. (2011). Sosyal Bilgiler Dersi Öğretim Programının Sürdürülebilir Kalkınma Eğitimi Açısından İncelenmesi, Eğitim Bilimleri Araştırmaları Dergisi, 1(2): 49-65.

Keskin, E.B. (2012). Sürdürülebilir Kent Kavramına Farklı Bir Bakış: Yavaş Şehirler (Cittaslow), PARADOKS Ekonomi, Sosyoloji ve Politika Dergisi, 8(1): 81-99.

Kınsız, M. (2005). Mesleki Yabancı Dil Eğitiminin Sürdürülebilir Gelişmeye Katkıları, Selçuk Üniversitesi Sosyal Bilimler Enstitüsü Dergisi, 13: 259-270.

Korkmaz, M. ve Başkalkan, S.N. (2011). Eğirdir Gölü ve Çevresinde Turizm Gelişiminin Sürdürülebilirliği Üzerine Değerlendirmeler, SDÜ Orman Fakültesi Dergisi, 12: 62-69.

Koşan, A. (2006). Doğu Anadolu Bölgesi ‘Sürdürülebilir Kalkınma' Yönlü Turizm Projeleri ve Bir Değerlendirme, Atatürk Üniversitesi Sosyal Bilimler Enstitüsü Dergisi, 8(2): 435-454.

Lehtonen, M. (2004). The Environmental-Social Interface of Sustainable Development: Capabilities, Social Capital, Institutions, Ecological Economics, 49(2): 199-214. 
MacDonald, W.L. and Hara, N. (1994). Gender Differences in Environmental Concern among College Students, Sex Roles, 31(5/6): 369-374.

MasterCard (2011). Türkiye'nin Şehirleri Sürdürülebilirlik Araştırması. [Online]http://www.mastercard.com/tr/personal/tr/promotions/Turkiyenin_Illeri_Surdurulebili rlik_Arastirmasi.pdf [Erişim Tarihi: 08.02.2018].

Nkemngu, A.-A.P. (2017). The Urban-Rural Tourism Mix: A Partnership of Convenience or Sustainability Imperative. (Editör) Slocum, S.L. and Kline, C.: Linking Urban and Rural Tourism: Strategies in Sustainability içinde (ss.115-127) UK: CABI.

Oğuz, D., Çakcı, I. ve Kavas, S. (2011). Yükseköğretimde Öğrencilerin Çevre Bilinci, SDÜ Orman Fakültesi Dergisi, 12: 34-39.

Sadık, F. (2013). Öğretmen Adaylarının Çevresel Tutum ve Bilgi Düzeylerinin Çeşitli Değişkenler Açısından İncelenmesi, Pegem Eğitim ve Öğretim Dergisi, 3(4): 69-82.

SDG Index (2017), Sustainable Development Goals Index 2017. [Online] http://www.sdgindex.org/assets/files/2017/2017-SDG-Index-and-Dashboards-Report--full.pdf [Erişim Tarihi: 08.10.2018].

Sloan, P., Legrand, W. and Chen, J.S. (2009). Sustainability in the Hospitality Industry: Principles of Sustainable Operations. Great Britain: Butterworth-Heinemann.

Sözbilir, M. (2014). Nedensel Karşılaştırma Araştırma Yöntemi, (Editör) Metin, M.: Kuramdan Uygulamaya Ĕ̆itimde Bilimsel Araştırma Yöntemleri içinde (ss.115-135) Ankara: Pegem Akademi.

Talas, M. ve Karataş, A. (2012). Çevre Bilincinin Geliştirilmesinde Topluma Hizmet Uygulamaları Dersinin Önemi: Niğde Üniversitesi Sınıf Öğretmenliği Programı Örneği, Zeitschrift für die Welt der Türken, 4(1): 107-124.

Teksöz, G., Şahin, E. ve Ertepınar, H. (2010). Çevre Okuryazarlığı, Öğretmen Adayları ve Sürdürülebilir Bir Gelecek, Hacettepe Üniversitesi Eğitim Fakültesi Dergisi, 39: 307-320.

Tuna, M. ve Özdemir, G. (2016). Sürdürülebilir Turizm Kapsamında Karbon Ayak İzi, II. Ulusal Sürdürülebilir Turizm Kongresi, Akdeniz Üniversitesi 28-30 Nisan 2016, Antalya.

Türk, M. (2010). Çevre Bilinci - Yasal Zorunluluktan Sosyal Sorumluluğa. Ankara: Nobel Yayın Dağıtım.

UNESCO (1997). Educating for a Sustainable Future: A Transdisciplinary Vision for Voncerted Action. [Online] http://www.unesco.org/education/tlsf/mods/theme_a/popups/mod01t05s01.html [Erişim Tarihi: 08.09.2018].

UNESCO (2005). UNESCO and Sustainable Development. [Online] http://unesdoc.unesco.org/images/0013/001393/139369e.pdf [Erişim Tarihi: 08.09.2018].

UNESCO (2017). Education for Sustainable Development. [Online] https://en.unesco.org/themes/education-sustainable-development [Erişim Tarihi: 08.09.2018].

Wall, G. (1997). Is ecotourism sustainable?, Environmental Management, 21(4): 483-491.

WEF (2009). Sustainability for Tomorrow's Consumer the Business Case for Sustainability, World Economic Forum Report, REF: 150109.

Yıldız, Ş. (2011). Öğretmenlerin, Öğretmen Adaylarının ve Öğrencilerin Sürdürülebilir Çevre ile İlgili Kavramsal Anlamaları ve Tutumları, Yayımlanmamış Yüksek Lisans Tezi, Dokuz Eylül Üniversitesi, İzmir. 